\title{
Linking Low-Frequency Large- Scale Circulation Patterns to Cold Air Outbreak Formation in the Northeastern North Atlantic
}

\section{Journal Article}

Author(s):

Papritz, Lukas (1D; Grams, Christian M.

Publication date:

2018-03

Permanent link:

https://doi.org/10.3929/ethz-b-000255690

Rights / license:

$\underline{\text { In Copyright - Non-Commercial Use Permitted }}$

Originally published in:

Geophysical Research Letters 45(5), https://doi.org/10.1002/2017GL076921

\section{Funding acknowledgement:}

148177 - The mutual interaction of individual weather systems and weather regimes (SNF) 


\author{
RESEARCH LETTER \\ 10.1002/2017GL076921 \\ Key Points: \\ - Modulation of cold air outbreaks \\ (CAOs) by the large-scale circulation \\ is investigated \\ - Shifts of storm tracks during specific \\ weather regimes (WRs) are the key \\ factor modulating $\mathrm{CAO}$ occurrence \\ and air mass pathways \\ - Frequent cyclonic WRs during strong \\ polar vortex conditions favor CAOs
}

Supporting Information:

- Supporting Information S1

Correspondence to:

L. Papritz,

lukas.papritz@uib.no

\section{Citation:}

Papritz, L., \& Grams, C. M. (2018). Linking low-frequency large-scale circulation patterns to cold air outbreak formation in the northeastern North Atlantic. Geophysical Research Letters, 45, 2542-2553. https://doi.org/10.1002/2017GL076921

Received 13 OCT 2017 Accepted 16 FEB 2018 Accepted article online 22 FEB 2018 Published online 15 MAR 2018

\section{Linking Low-Frequency Large-Scale Circulation Patterns to Cold Air Outbreak Formation in the Northeastern North Atlantic}

\author{
L. Papritz ${ }^{1,2}$ and C. M. Grams ${ }^{3,4}(\mathbb{D}$ \\ ${ }^{1}$ Geophysical Institute, University of Bergen, Bergen, Norway, ${ }^{2}$ Bjerknes Centre for Climate Research, Bergen, Norway, \\ ${ }^{3}$ Institute for Atmospheric and Climate Science, ETH Zürich, Zürich, Switzerland, ${ }^{4}$ Institute for Meteorology and Climate \\ Research (IMK-TRO), Karlsruhe Institute of Technology, Karlsruhe, Germany
}

Abstract The regional variability of wintertime marine cold air outbreaks (CAOs) in the northeastern North Atlantic is studied focusing on the role of weather regimes in modulating the large-scale circulation. Each regime is characterized by a typical CAO frequency anomaly pattern and a corresponding imprint in air-sea heat fluxes. Cyclonically dominated regimes, Greenland blocking and the Atlantic ridge regime are found to provide favorable conditions for CAO formation in at least one major sea of the study region; CAO occurrence is suppressed, however, by blocked regimes whose associated anticyclones are centered over northern Europe (European / Scandinavian blocking). Kinematic trajectories reveal that strength and location of the storm tracks are closely linked to the pathways of CAO air masses and, thus, CAO occurrence. Finally, CAO frequencies are also linked to the strength of the stratospheric polar vortex, which is understood in terms of associated variations in the frequency of weather regimes.

Plain Language Summary Marine cold air outbreaks (CAOs) bring about adverse weather and lead to intense cooling of the ocean surface. This cooling plays an especially important role in the Nordic Seas, where dense waters are formed that feed into the Atlantic meridional overturning circulation. Variations in the occurrence of such CAOs, therefore, are of fundamental importance in the coupled atmosphere-ocean climate system. In this study, we link persistent states of the large-scale atmospheric circulation over the North Atlantic to the variability of CAOs in the Nordic Seas and the pathways of associated air masses. Our findings reveal that CAO occurrence is primarily modulated by shifts in location and strength of the storm tracks. Periods with intense storm tracks are particularly favorable for the formation of CAOs, thus, leading to enhanced heat loss of the ocean. In contrast, periods dominated by blocking anticyclones tend to suppress $\mathrm{CAO}$ formation, unless the anticyclone is located over Greenland. An important implication of our findings is that winters with an especially weak stratospheric polar vortex, which are accompanied by less active storm tracks and more blocking anticyclones, CAOs, are less frequent and heat loss of the ocean is reduced.

\section{Introduction}

Marine cold air outbreaks (CAOs) in the Arctic are often accompanied by severe weather - such as polar lows (e.g., Rasmussen \& Turner, 2003) and high near-surface wind speeds (Kolstad, 2017) — and they play a fundamental role in the climate system by modulating the spatiotemporal variability of air-sea heat exchanges (Brümmer, 1996; Fletcher et al., 2016; Grossman \& Betts, 1990; Jensen et al., 2011; Renfrew \& Moore, 1999; Shapiro et al., 1987). Climatologically CAOs contribute the bulk to the wintertime cooling of high-latitude oceans by sensible and latent heat fluxes (Harden et al., 2015; Papritz \& Spengler, 2017; Papritz et al., 2015). Thus, CAOs, in the Nordic Seas in particular, provide an important forcing of the Atlantic meridional overturning circulation (e.g., Buckley \& Marshall, 2016). In this region CAOs form preferentially when cold, polar air masses flow down from Greenland's ice shelf or across the sea ice edge over open ocean (Brümmer, 1996; Mallet et al., 2013; Papritz \& Spengler, 2017; Wacker et al., 2005). Diminishing sea ice extent in the western Nordic Seas (Fauria et al., 2010) and strong interannual variability of the large-scale atmospheric circulation in the Euro-Atlantic sector (e.g., Hanna et al., 2015) affects CAO occurrence, which in turn directly modulates
O2018. American Geophysical Union. All Rights Reserved. 
the wintertime air-sea heat flux forcing of the ocean with implications for dense water formation (Moore et al., 2015). Understanding the relationship between the large-scale flow and the variability of CAO occurrence in that region is therefore an important factor in our understanding of the coupled atmosphere-ocean climate system.

In previous work, the formation and variability of CAOs have been linked to bimodal hemispheric and large-scale circulation patterns. For example, Kolstad et al. (2009) found a strong correlation between the North Atlantic Oscillation (NAO) and the occurrence of CAOs in the Irminger Sea. In the Nordic Seas a major part of the air masses that lead to CAOs there exit from the interior Arctic via Fram Strait (Papritz \& Spengler, 2017). Hence, it can be expected that CAO occurrence in the Nordic Seas is favored by flow configurations that are associated with northerly flow over Fram Strait. In particular, positive relationships have been found between winds over Fram Strait and the NAO, as well as the Arctic Oscillation (AO; Rigor et al., 2002; Zhang et al., 2003) - yet an important portion of the variability over the Nordic Seas remains controlled by flow patterns that are uncorrelated with the NAO such as the Iceland-Lofoten dipole in sea level pressure (Jahnke-Bornemann \& Brümmer, 2009). Consequently, the correspondence between the phase of the NAO and the occurrence of CAOs in the Nordic Seas is relatively weak (Kolstad et al., 2009), suggesting that large-scale circulation patterns other than the NAO and AO exert a strong control on CAO variability in this region.

From a weather system perspective both anticyclones and cyclones can in principle induce CAOs. For example, episodes of persistent blocking over northern Europe are known to favor CAOs over continental Europe and Scandinavia (Buehler et al., 2011), while anticyclones over Greenland can induce CAOs over the Nordic Seas (Kolstad, 2017; Kolstad et al., 2009) and the Irminger Sea (Papritz, 2017). Often, however, marine CAOs are also embedded in the equatorward flow on the rearward side of extratropical cyclones (Fletcher et al., 2016; Vannière et al., 2016; Zolina \& Gulev, 2003). Hence, one or several persistent anticyclones or a sequence of cyclones following similar pathways that deviate substantially from the climatological storm track may result in significant seasonal anomalies of CAO frequency.

In addition to tropospheric weather systems, also, the strength of the stratospheric polar vortex has previously been linked to CAOs at mid- and high latitudes via its influence on the tropospheric circulation (Cai \& Ren, 2007; Cai et al., 2015; Kidston et al., 2015; Thompson \& Wallace, 2001), with, in particular, a tendency for anomalous cold Eurasia and North America in the aftermath of weak vortex events (Cellitti et al., 2006; Kim et al., 2014; Kidston et al., 2015; Kolstad et al., 2010; Thompson et al., 2002). Furthermore, CAOs during periods of a weak stratospheric polar vortex have been linked to an enhanced frequency of high-latitude blocking (e.g., Kidston et al., 2015).

This study aims to systematize those previous findings about the variability of CAOs by a quantitative investigation of the linkage between the low-frequency large-scale atmospheric circulation patterns and CAOs in a subregion of the North Atlantic, namely, the Nordic Seas and the proximate Irminger and Barents Seas (cf. Figure $1 \mathrm{~h}$ for location names), where the air-sea heat flux forcing imposed by CAOs plays an especially important role for the forcing of the Atlantic meridional overturning circulation. Specifically, this paper addresses the following questions:

1. Which low-frequency circulation states are conducive for CAOs in this particular region?

2. Where does CAO formation preferentially occur and what are the airmass pathways during each such circulation state?

3. Do winters with a weak polar vortex show more frequent CAOs?

To address these questions, we combine a weather regime (WR) classification with a recent CAO climatology using kinematic trajectories. WRs are an established, systematic, and quantitative framework to describe quasi-stationary, persistent, and recurrent states of the large-scale atmospheric circulation in the Euro-Atlantic sector (Cassou, 2008; Mallet et al., 2013; Michel \& Rivière, 2011; Michelangeli et al., 1995; Vautard, 1990). WRs typically extend over continent-sized regions and modulate the characteristics of surface weather for several days to a few weeks. In contrast to the bimodal NAO or the AO, WRs explain almost the full range of variability in the large-scale circulation and, thus, are suited to systematically investigate the variability in the formation of CAOs in the Nordic Seas. This approach will be described in the following section. 
Atlantic trough

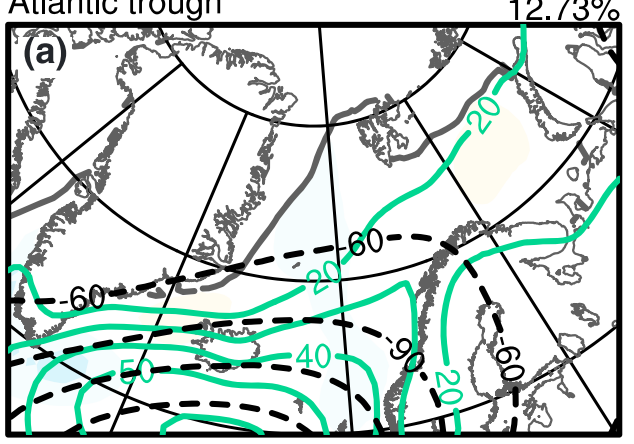

Scandinavian trough

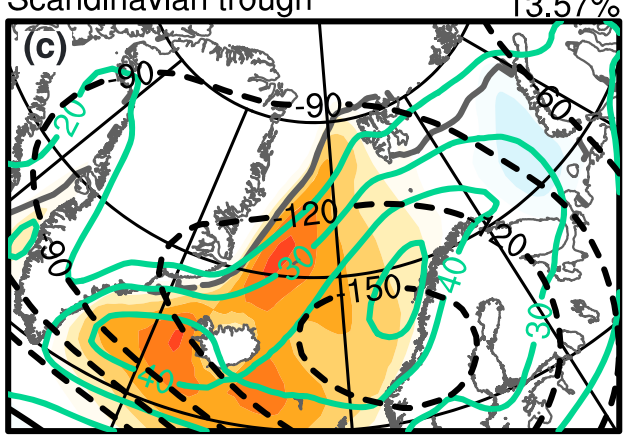

European blocking

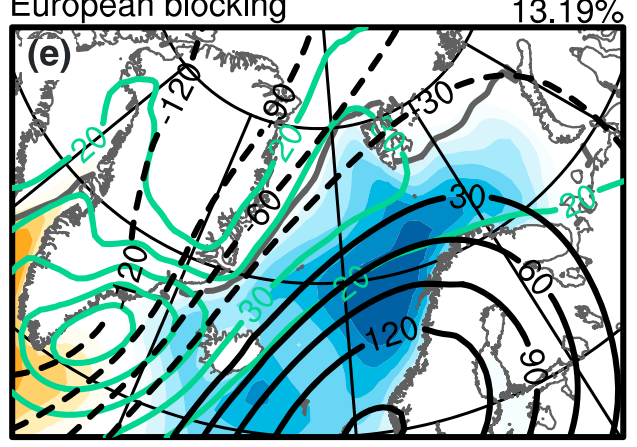

Greenland blocking

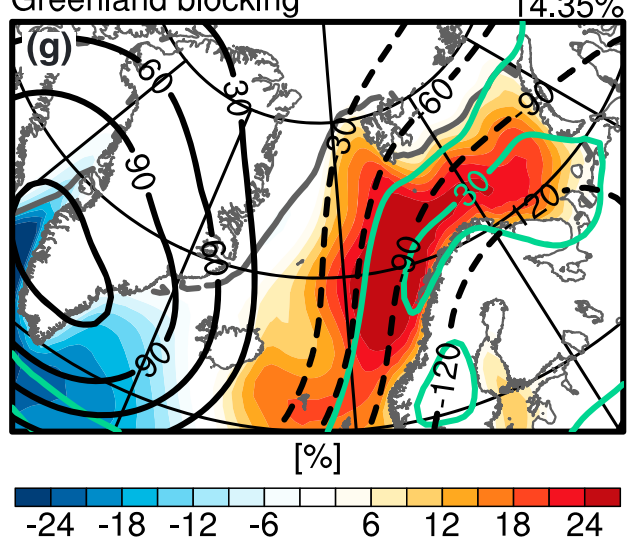

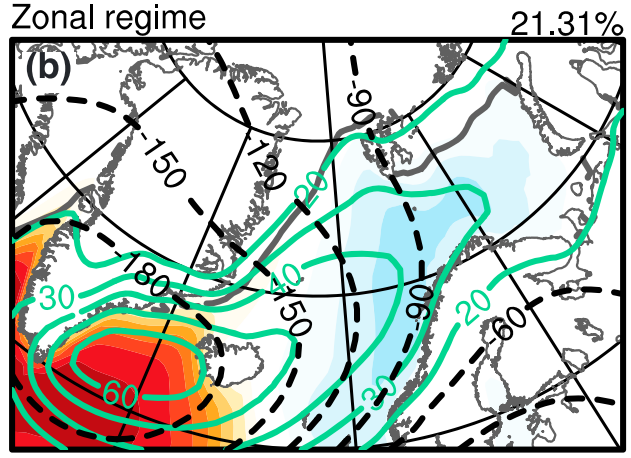

Atlantic ridge

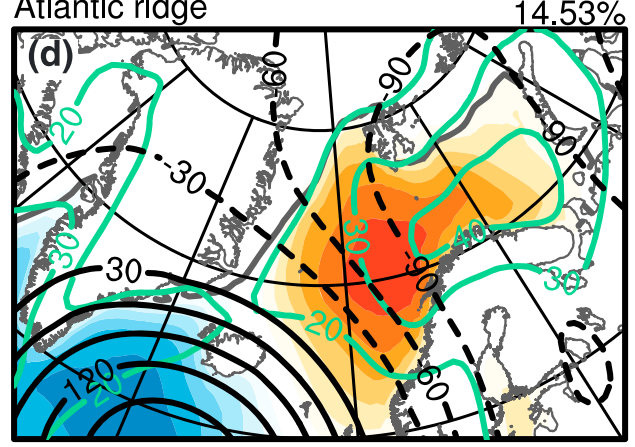

Scandinavian blocking

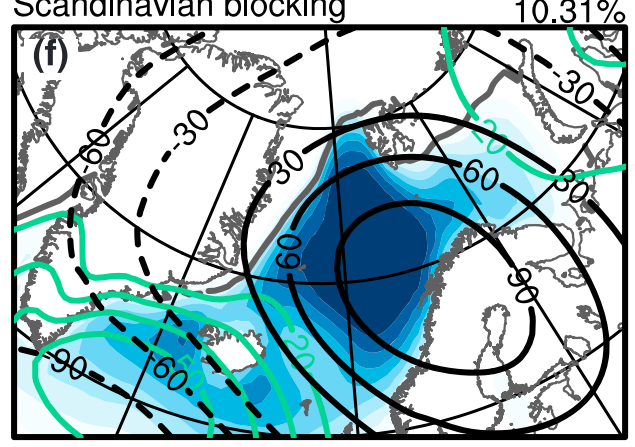

Climatology

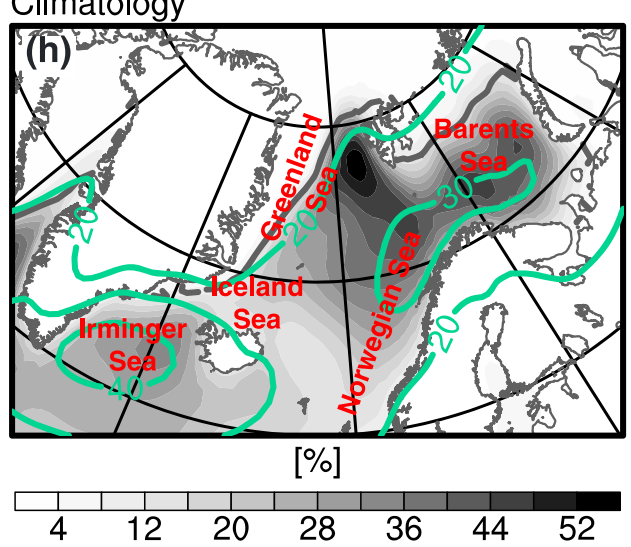

Figure 1. (a-g) Composites for the seven regimes of $500 \mathrm{hPa}$ geopotential height anomaly (black, in intervals of $30 \mathrm{~m}$, dashed lines indicate negative values), cyclone frequency (green, from $20 \%$ in intervals of $10 \%$ ), and CAO frequency anomaly (shading). The mean frequency of the corresponding regime during November to April is indicated in the top right of each panel. Panel (h) shows the winter climatology of cyclone frequency (green, from $20 \%$ in intervals of $10 \%$ ) and CAO frequency (shading). The climatological winter mean sea ice edge (50\% sea ice concentration) is indicated in gray. In addition, in (h) the location of the major seas is shown. The Nordic Seas comprise the Norwegian, Greenland, and Iceland Seas. 


\section{Data and Methodology}

The study is based on the Interim reanalysis data set issued by the European Centre for Medium-Range Weather Forecasts. We consider extended winters spanning November to April — the months when CAOs are most frequent - from 1980 to 2015. For identifying CAOs we use the air-sea potential temperature difference, thereby following previous works on CAOs (e.g., Fletcher et al., 2016; Kolstad \& Bracegirdle, 2008; Papritz \& Spengler, 2017; Papritz et al., 2015). Specifically, we consider 6-hourly fields of $\theta_{\mathrm{SST}}-\theta_{900}$, where $\theta_{\mathrm{SST}}$ is potential sea surface temperature and $\theta_{900}$ denotes potential temperature at $900 \mathrm{hPa}$. Values of $\theta_{\mathrm{SST}}-\theta_{900}$ in excess of $4 \mathrm{~K}$ indicate a moderate to intense CAO (cf. Papritz \& Spengler, 2017). Thus, grid points where this threshold is exceeded are considered as CAO grid points. From the so-identified grid points climatological frequencies of CAOs are computed.

Trajectories sampling CAO air masses are computed following the method of Papritz and Spengler (2017) and using the Lagrangian analysis tool (LAGRANTO; Sprenger \& Wernli, 2015). From the trajectories CAO formation rates and CAO air mass fluxes, which indicate the pathways of CAO air masses prior to CAO formation, are derived. CAO formation denotes the time when $\theta_{\mathrm{SST}}-\theta_{900}>4 \mathrm{~K}$ for the first time along the trajectories. In contrast to Papritz and Spengler (2017) not the entire CAO air masses are sampled by trajectories. Instead, only the air masses at a pressure in the range of $925 \mathrm{hPa}<p<875 \mathrm{hPa}$ at the time of CAO formation are considered. This ensures consistency with the Eulerian identification of CAO frequencies based on $\theta_{\mathrm{SST}}-\theta_{900}$.

We employ the extended year-round WR classification of Grams et al. (2017) providing seven different large-scale flow patterns. This classification builds on previous work by Michelangeli et al. (1995), Cassou (2008), and Ferranti et al. (2015) that rather focused on one specific season, that is, summer or winter. The extended seven WRs reflect the variability in large-scale flow patterns across all seasons, which is important for our study since we are interested in extended winters that include part of the shoulder seasons. Furthermore, the seven WRs reveal detailed characteristics of the variability of the large-scale flow in the subregion of the North Atlantic considered here. Consistent with earlier work, the WRs are obtained from a k-means clustering in the phase space spanned by the first seven empirical orthogonal functions (EOFs) of low-pass filtered, normalized $500 \mathrm{hPa}$ geopotential height anomalies in the Euro-Atlantic sector $\left(80^{\circ} \mathrm{W}-40^{\circ} \mathrm{E}, 30^{\circ} \mathrm{N}-90^{\circ} \mathrm{N}\right.$; Grams et al., 2017). Geopotential height anomalies are defined with respect to the 90 day running mean of the climatology for the respective date. Unlike Grams et al. (2017) regime life cycles are not considered here; instead, each date is uniquely assigned to the cluster closest in distance. Note that in contrast to the bimodal NAO or AO, which are typically derived from the first EOF explaining about $20-25 \%$ of the variance, WRs are based on the seven leading EOFs explaining about $75 \%$ of the variance and thus cover almost the full range of large-scale flow variability.

To characterize the storm tracks, we use extended winter mean cyclone frequencies derived from sea level pressure with the method by Wernli and Schwierz (2006). In addition, we investigate the linkage of CAOs and the state of the stratospheric polar vortex, thereafter simply referred to as the polar vortex, during winter months (December, January, February). Following (Ambaum \& Hoskins, 2002), we define the winter mean strength of the polar vortex as the December to February mean standardized potential vorticity on the $530 \mathrm{~K}$ potential temperature level spatially averaged over the polar cap $\left(>60^{\circ} \mathrm{N}\right)$. Weak and strong polar vortex winters are identified as winters with standardized potential vorticity below -0.5 and above 0.5 , respectively.

\section{Results}

First, we provide an overview over the seven WRs in terms of their signature in $500 \mathrm{hPa}$ geopotential height anomalies and their associated impact on the storm track and frequency of CAOs (Figure 1). In addition, we discuss the modulation of CAO air mass pathways and CAO formation regions (Figure 2). For reference we also display corresponding climatological fields (Figures $1 \mathrm{~h}$ and $2 \mathrm{~h}$ ). Of the total seven WRs, three are dominated by negative $500 \mathrm{hPa}$ geopotential height anomalies (Figures 1a-1c), thereafter referred to as cyclonic regimes, and four are dominated by positive anomalies (Figures $1 \mathrm{~d}-1 \mathrm{~g}$ ), thus, referred to as blocked regimes. The cyclonic regimes, as well as to a lesser extent the European Blocking regime, project positively on the NAO, while Greenland blocking projects negatively. The remaining blocked regimes, in contrast, show no strong link to the NAO with only weakly negative values of the NAO index (cf. supporting information Table S1 in Grams et al., 2017). 

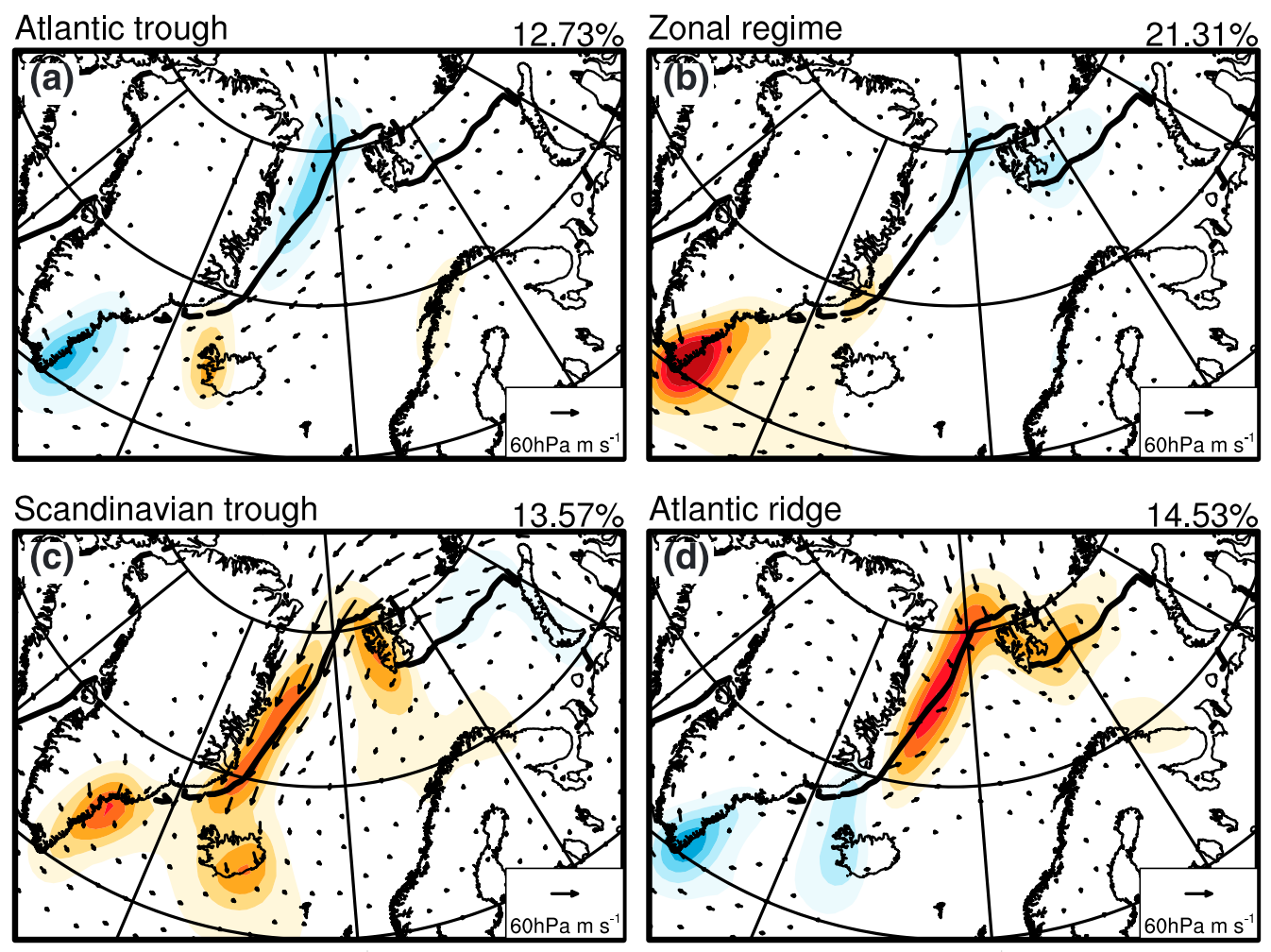

European blocking
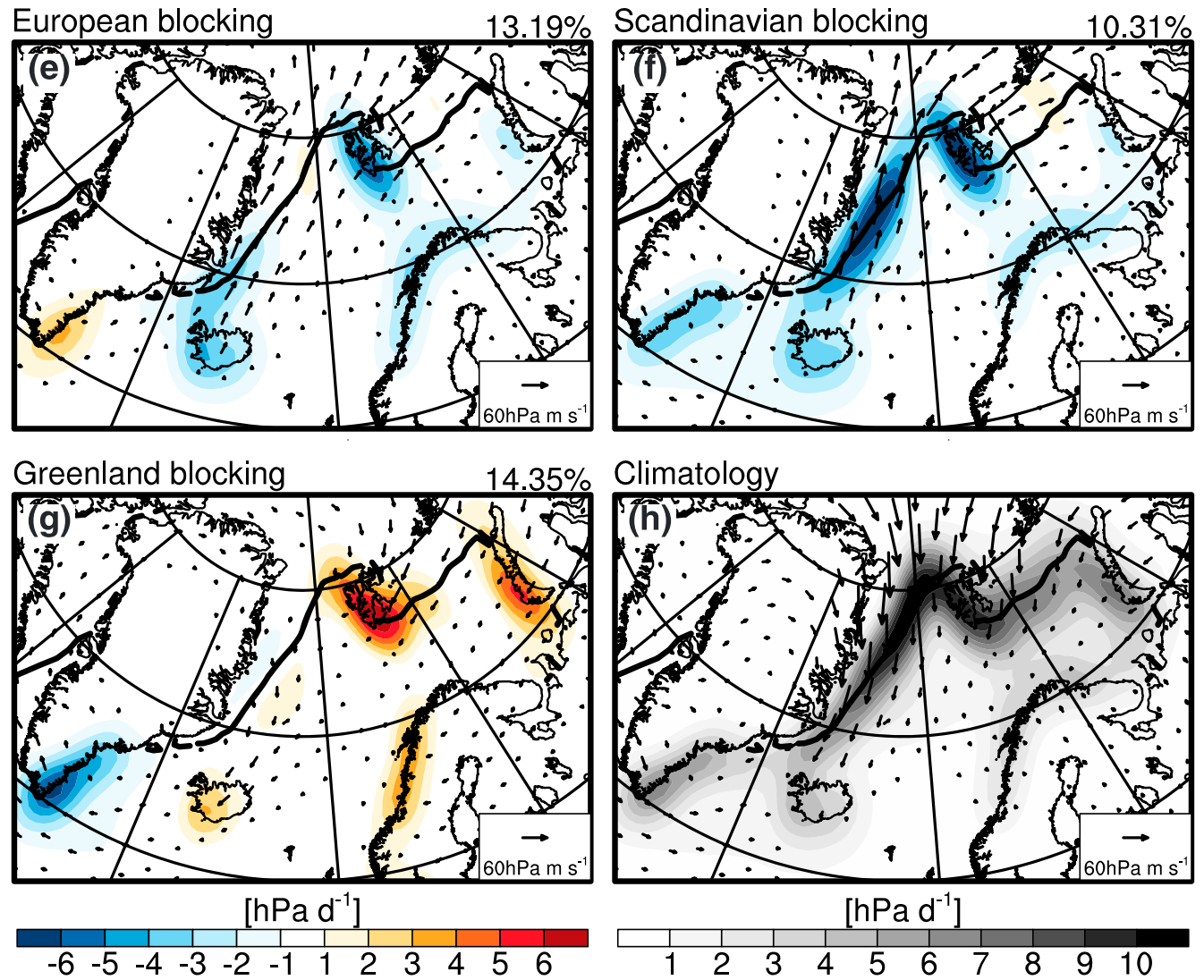

Figure 2. As in Figure 1 but for anomalies $(\mathrm{a}-\mathrm{g})$ of $\mathrm{CAO}$ mass fluxes before $\mathrm{CAO}$ formation (black vectors) and anomalies of CAO formation rate (shading). (h) Anomalies with respect to the climatology. 


\subsection{Cyclonic Regimes}

In general, the cyclonic regimes provide favorable conditions for CAO formation in the Irminger Sea, as well as the Iceland and Greenland Seas, as they are associated with particularly high cyclone frequencies in the Irminger Sea and the Nordic Seas. There are, however, differences in strength and location of CAO frequency anomalies between the three regimes, as well as on a regional basis within the regimes. These variations are related to strength and location of the storm tracks with positive CAO frequency anomalies being most pronounced west or southwest of cyclone frequency maxima, as we discuss in the following.

The Atlantic trough regime is associated with a negative $500 \mathrm{hPa}$ geopotential height anomaly with its center located well south of Iceland, as well as collocated high cyclone frequency. The location of this cyclone frequency maximum is unfavorable for inducing substantial positive anomalies in the southward transport of polar cold air masses. Hence, the modulations of CAO occurrence and CAO air mass transports with respect to climatology in this regime are weak (Figures 1a and 2a).

In contrast, in the zonal regime (Figures $1 \mathrm{~b}$ and $2 \mathrm{~b}$ ) the center of the trough is located over southern Greenland and favors lee cyclogenesis in the Irminger Sea (Wernli \& Schwierz, 2006; Dacre \& Gray, 2009), resulting in a cyclone frequency of more than $60 \%$ there. The westerly winds over southern Greenland in the midtroposphere and the cyclonic flow near the surface over the Irminger Sea induce an anomalous transport of CAO air masses originating in the Canadian Arctic, overflowing the southern tip of Greenland and descending into the Irminger Sea (cf. Figure 2b; Papritz, 2017). Accordingly, CAO frequency within the Irminger Sea is strongly enhanced with a local maximum located south of the cyclone frequency maximum.

The Scandinavian trough regime (Figures $1 \mathrm{c}$ and $2 \mathrm{c}$ ), finally, is characterized by a trough centered over Scandinavia that extends into the Nordic Seas. It is associated with two local maxima of cyclone frequency - one in the Irminger Sea and a second one in the Norwegian Sea with a center near the Lofoten archipelago. This cyclone frequency configuration is akin to the archetypal synoptic pattern favorable for establishing a long-range southward transport of CAO air masses from Fram Strait along Greenland's east coast (cf. also Papritz, 2017), thus, leading to positive CAO frequency anomalies from the ice edge of the Greenland and Iceland Seas into the Norwegian Sea, as well as the Irminger Sea. In addition, also, enhanced flow of CAO air masses over southern Greenland occurs, leading to CAO formation in the Ammassalik region.

\subsection{Blocked Regimes}

The blocked regimes have an ambiguous impact on CAOs. On the one hand, European and Scandinavian blocking are associated with less frequent propagation of cyclones into the Nordic Seas and therefore CAO frequency over most of the basins is weak (Figures 1e and 1f), whereas, on the other hand, the Atlantic ridge and Greenland blocking are associated with frequent cyclones in the Norwegian and the Barents Seas, thus, leading to strongly positive CAO frequency anomalies over large parts of the Nordic Seas and the Barents Sea (Figures 1d and 1g).

The Atlantic ridge is characterized by a positive $500 \mathrm{hPa}$ geopotential height anomaly southwest of Iceland and a negative anomaly extending far into the Barents Sea (Figure 1d). A high frequency of cyclones is collocated with the negative $500 \mathrm{hPa}$ geopotential height anomaly in the Barents Sea, where notable cyclone frequencies extend as far north as the Svalbard archipelago and farther into the Greenland Sea. In this regime, CAO frequency is strongly enhanced west of the cyclone frequency maximum. This anomaly is associated with amplified southward CAO air mass fluxes through Fram Strait toward the sea ice edge in the Greenland Sea and near Svalbard (Figure 2d).

In European blocking a positive $500 \mathrm{hPa}$ geopotential height anomaly is located between the British Isles and Scandinavia extending into the Norwegian Sea (Figure 1e). The storm track in the Nordic Seas is strongly displaced toward Greenland, with notable cyclone frequencies being confined to the western Irminger Sea and along the sea ice edge of the Iceland and Greenland Seas. Consequently, warm advection in the warm sectors of these cyclones dominates over much of the Nordic Seas. With respect to climatology, CAO air mass fluxes from Fram Strait into the Nordic Seas, and CAO formation near Svalbard and in the Iceland Sea is thus substantially reduced (Figure 2e), resulting in strongly negative CAO frequency anomalies, especially in the Norwegian Sea.

The synoptic features of Scandinavian blocking (Figure 1f) are similar to those in European blocking but rotated in the anticlockwise direction with positive $500 \mathrm{hPa}$ geopotential height anomalies centered over Scandinavia and extending largely over the Nordic Seas. Southward CAO air mass transports from Fram Strait 
and northern Greenland, and CAO formation along the sea ice edge in the Greenland and Iceland Seas, as well as near Svalbard, is suppressed (Figure 2f). Consequently, this regime is associated with the most negative CAO frequency anomalies throughout the Nordic Seas and the Irminger Sea.

In the case of Greenland blocking a positive $500 \mathrm{hPa}$ geopotential height anomaly is centered over southern Greenland and a negative one extends over Scandinavia (Figure 1g). High cyclone frequencies are found off the coast of Norway and in the southern Barents Sea, thus giving rise to frequent episodes of northerly CAO air mass fluxes over and near Svalbard, as well as easterly fluxes over Nowaya Zemlya (Figure $2 \mathrm{~g}$ ). This results in a strong CAO frequency anomaly in the Norwegian and Barents Seas (Figure 1g).

In summary, the cyclonic regimes lead to an enhanced CAO frequency in the western and northwestern parts of the study region, that is, in the Irminger, Iceland, and Greenland Seas. The impact of blocked regimes depends critically on the location of the blocked anticyclone and the associated shift or reduction of cyclone activity. Blocked regimes with the anticyclone located to the west of the study domain, that is, Greenland blocking and the Atlantic ridge, favor CAOs in the eastern parts, whereas anticyclones over Scandinavia or Europe suppress CAO formation all over the Nordic Seas.

A note is due regarding the sensitivity of these findings with respect to the choice of threshold for the identification of CAO air masses. Using a more stringent threshold of $8 \mathrm{~K}$ that selects intense CAOs only, we find similar spatial patterns of CAO frequency anomalies that are consistent with the previously discussed flow anomalies (supporting information Figure S1). Large anomalies are, however, more confined toward the CAO formation regions along the sea ice edge, where polar air masses are coldest and such intense CAOs are therefore more frequent.

\subsection{Surface Heat Fluxes}

Climatologically, CAOs contribute between 60 and $80 \%$ to the winter mean upward sensible and latent heat fluxes (Papritz \& Spengler, 2017). By modulating CAO frequency, WRs therefore should have a strong imprint in surface heat fluxes. Indeed, heat flux anomalies associated with each of the regimes are well collocated with according anomalies in CAO frequency (cf. Figure 3). In addition to CAOs, also, variations in the frequency of high wind speeds (e.g., in excess of $20 \mathrm{~m} \mathrm{~s}^{-1}$ ) associated with extratropical cyclones and their interaction with orography may locally induce enhanced surface heat fluxes. In particular, intense barrier winds along Greenland's southeast coast are prevalent as the result of cyclonic flow impinging on the steep orography (e.g., Harden et al., 2011). This is often the case in the Atlantic trough regime, thus leading to enhanced surface heat fluxes near Denmark Strait (Figure 3a), which due to the only weakly enhanced CAO frequency must be attributed to enhanced vertical mixing associated with the barrier winds. Furthermore, also, the other cyclonic regimes are accompanied by a slightly enhanced frequency of high wind speeds from the Denmark Strait to the western Iceland Sea, thereby amplifying the already enhanced heat loss of the ocean to the atmosphere due to more frequent CAOs.

\subsection{Role of Polar Vortex}

In Figure 4a we compare the standardized strength of the stratosphere polar vortex with the frequency of WRs during December, January, February. In line with the tendency for a more positive NAO and storm tracks being more confined to higher latitudes when the polar vortex is strong (Baldwin \& Dunkerton, 2001), cyclonic WRs are more frequent, whereas blocked regimes are less frequent (cf. Beerli, 2017 chapter 4.2). A weak polar vortex, in contrast, goes along with a higher likelihood for blocked regimes and less frequent cyclonic regimes. Specifically, taking our definition of the winter mean strength of the polar vortex into account, we find a relative increase in the frequency of the zonal and the Scandinavian trough regimes of around $40 \%$ each and a decrease of more than $60 \%$ for Greenland blocking, as well as of $20-30 \%$ for European and Scandinavian blocking (supporting informatoin Figure S2a). Likewise, we find for winters with a weak polar vortex a decrease of the relative frequencies of the zonal and Scandinavian trough regimes of around $50 \%$ and $30 \%$, respectively, while the frequency of Scandinavian and Greenland blocking is enhanced by roughly $25 \%$ and $60 \%$ respectively (supporting information Figure S2b).

In the Irminger as well as in the Iceland and Greenland Seas (Figure 4b) a strong polar vortex consequently implies a higher frequency of CAOs and enhanced surface sensible and latent heat fluxes, whereas a weak polar vortex goes along with a reduction of CAO frequency and of surface heat fluxes (Figure 4c). Interestingly, the frequency of CAOs in the Norwegian and Barents Seas is not strongly influenced by the strength of the polar vortex. The reason for this behavior can again be understood in terms of the individual WRs. 

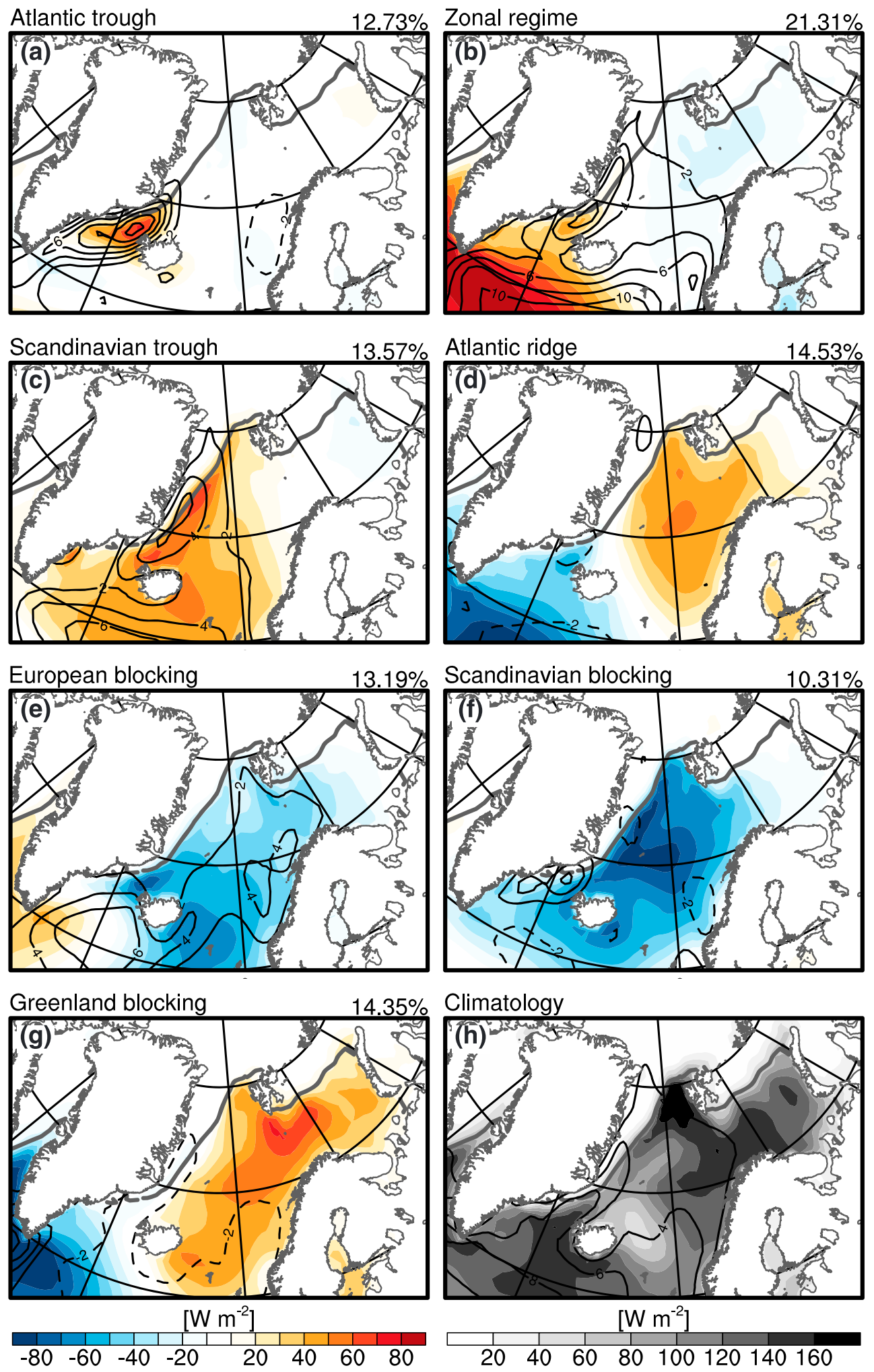

Figure 3. As in Figure 1 but for anomalies ( $\mathrm{a}-\mathrm{g}$ ) and climatology (h) of sensible and latent heat fluxes (shading) and frequency of wind speeds on the third model level ( $90 \mathrm{~m}$ above ground level) in excess of $20 \mathrm{~m} \mathrm{~s}^{-1}$ (black, in intervals of $2 \%$, dashed lines indicate negative values). 


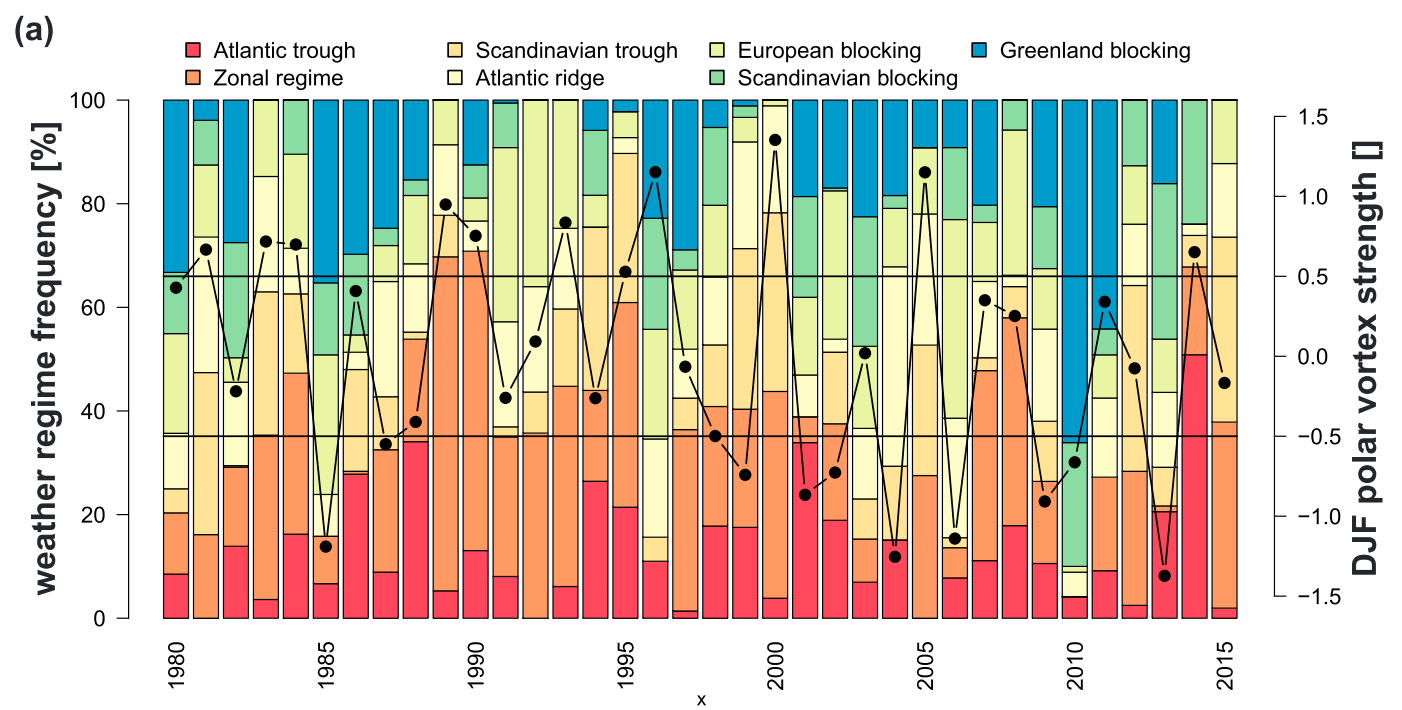

(b) strong polar vortex

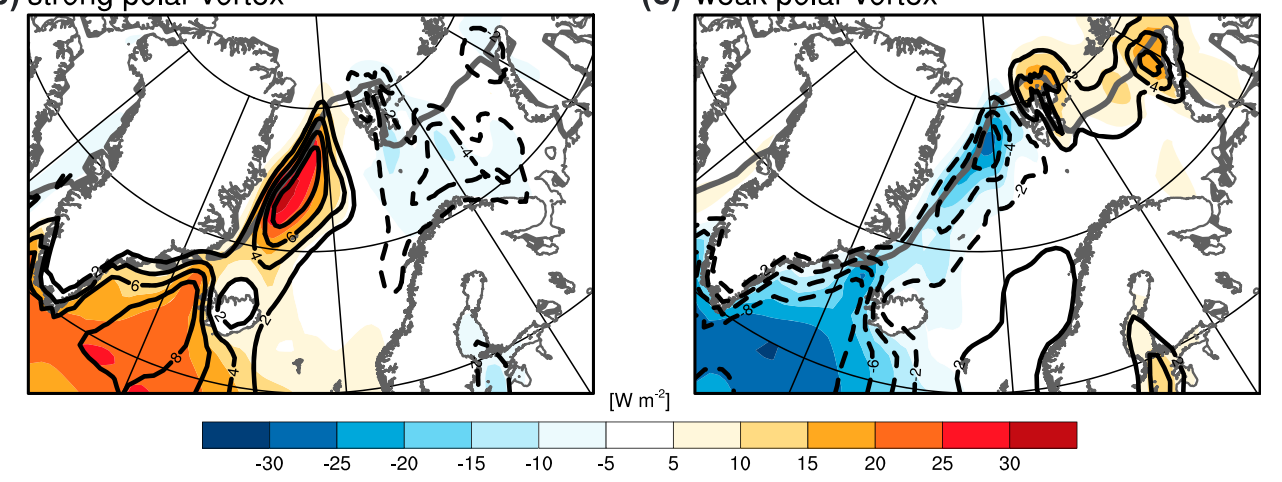

Figure 4. (a) Frequency of weather regimes during winter (December to February, color) and strength of polar vortex (black) with winter 1979/1980 being denoted as 1980. (b, c) Turbulent air-sea heat fluxes (shading) and CAO frequency anomaly (black, in intervals of $2 \%$, dashed lines indicate negative values) for winters (December to February) with strong (b) and weak (c) polar vortex. The composite sea ice edge (50\% sea ice concentration) in the respective winters is indicated in gray.

The cyclonic regimes generally have a rather weak influence on CAO frequency there (Figures 1a-1c). The blocked regimes, in contrast, affect CAO frequency in a subtly more nuanced way: the European and Scandinavian blocking regimes both suppress CAOs, whereas Greenland blocking and the Atlantic ridge regimes favor them (Figures $1 \mathrm{~d}-1 \mathrm{~g}$ ). Thus, CAO frequency anomalies associated with frequency variations of each of the blocked regimes during winters with an anomalously strong or weak polar vortex mutually compensate each other.

It is noteworthy that an enhancement of CAO frequency during weak polar vortex winters can be observed along the sea ice edge of the Barents Sea (Figure 4c). This may be caused by the increased frequency of Greenland blocking and therefore enhanced CAO formation. However, this is likely in part also owed to the fact that such weak polar vortex winters have been more frequent in the past decade (cf. Figure 4a) when the sea ice extent in the Barents Sea has declined dramatically and the northern sea ice edge in the Barents Sea has been shifted poleward (e.g., Cavalieri \& Parkinson, 2012), hence, leaving more open water exposed to the atmosphere than in the earlier decades.

\section{Concluding Remarks}

In this study we have identified nuanced spatial modulations of CAO frequency and air mass pathways in the Nordic Seas and the adjacent Irminger and Barents Seas by the predominant low-frequency large-scale circulation patterns in the Euro-Atlantic sector during extended winters (November to April) 1980 to 2015. 
Concluding from our analysis, $\mathrm{CAO}$ occurrence in at least one major sea of the study region can be expected during three quarters of an extended winter period. Those regimes favorable for CAO formation can comprise both cyclonic and blocked large-scale flow features. In particular, we find that the locations of the storm tracks, measured here in terms of cyclone frequency, are closely linked to where cold, polar air masses are advected over open ocean, and thus, CAO formation occurs. The sole regimes systematically suppressing CAO formation over the entire Nordic Seas, the Irminger Sea, and the Barents Sea are associated with anticyclones either over northern Scandinavia (Scandinavian blocking) or southern Scandinavia and the British Isles (European blocking).

Thompson et al. (2002) and Kolstad et al. (2010) found an enhanced likelihood for CAOs to occur over continental Europe and Scandinavia in the aftermath of stratospheric weak polar vortex events. Interestingly, this finding does not translate into the Nordic Seas and its surrounding ocean basins in terms of winters characterized by an overall weak polar vortex. On the contrary, in the Irminger Sea and along the sea ice edge of the Greenland and Iceland Seas, CAOs are more frequent in winters with a strong polar vortex and vice versa when the polar vortex is weak. In addition, the strength of the polar vortex does not systematically influence winter mean CAO frequency in the Norwegian and the Barents Seas. The major reason is an enhanced frequency of cyclonic WRs when the polar vortex is strong, which is consistent with a poleward contraction of the storm track and a tendency for a more positive NAO (Baldwin \& Dunkerton, 2001). However, the mutual compensation of $\mathrm{CAO}$ frequency anomalies associated with the opposed modulations by blocked regimes explains the absence of a mean signal during weak polar vortex conditions.

Our study provides a link between the low-frequency large-scale circulation in the Euro-Atlantic sector and the occurrence of CAOs. This link may help to improve forecasts of outbreaks of polar lows (Mallet et al., 2013; Michel et al., 2018), which tend to develop along the baroclinic edge of CAOs (Terpstra et al., 2016). Furthermore, it may also help to better understand variations in the air-sea heat flux forcing imparted on the ocean-variations that are associated with interannual variability of the large-scale circulation in the Euro-Atlantic sector in the past decade, such as the enhanced variability of the NAO and blocking over Greenland (Hanna et al., 2015), as well as recent extreme states of the NAO (e.g., Cattiaux et al., 2010). Long-term future changes of $\mathrm{CAO}$ occurrence in the Nordic Seas in a warming climate, in contrast, may not primarily be caused by changes of the large-scale circulation. In fact, climate integrations indicate that the frequency of Euro-Atlantic WRs in a considerably warmer climate will undergo modest changes only (Mallet et al., 2017). Hence, long-term changes in the occurrence of CAOs over the Nordic Seas in a warming climate will most likely be dominated by changes in the availability of cold (with respect to SST) air masses and shifts in CAO formation regions associated with the retreating ice edge (e.g., Fauria et al., 2010).

Acknowledgments

The authors thank Remo Beerli for stimulating discussions and the ECMWF for providing the ERA-Interim reanalysis. L. P. and C. M. G. acknowledge support by the Swiss National Science Foundation (SNSF) grants P2EZP2_162267, and P300P2_174307 and PZ00P2_148177/1, respectively. C. M. G. was additionally supported by a Bjerknes Visiting Fellowship from the Bjerknes Centre for Climate Research. The ERA-Interim reanalysis is available from http://www.ecmwf.int, and derived quantities are available through the methodologies described and referenced in section 2 . For questions please contact any of the authors.

\section{References}

Ambaum, M. H. P., \& Hoskins, B. J. (2002). The NAO troposphere-stratosphere connection. Journal of Climate, 15, 1969-1978. https://doi.org/10.1175/1520-0442(2002)015<1969:TNTSC >2.0.CO;2

Baldwin, M. P., \& Dunkerton, T. J. (2001). Stratospheric harbingers of anomalous weather regimes. Science, 294, $581-584$. https://doi.org/10.1126/science.1063315

Beerli, R. (2017). Sources of sub-seasonal predictability for energy industry-relevant weather events (PhD thesis). Institute for Atmospheric and Climate Science, ETH Zürich, Zürich, Switzerland, Diss. ETH. No. 24488. Retrieved from http://www.library.ethz.ch

Brümmer, B. (1996). Boundary-layer modification in wintertime cold-air outbreaks from the Arctic sea ice. Boundary-Layer Meteorology, 80, 109-125. https://doi.org/10.1007/BF00119014

Buckley, M. W., \& Marshall, J. (2016). Observations, inferences, and mechanisms of Atlantic Meridional Overturning Circulation variability: A review. Reviews of Geophysics, 54, 5-63. https://doi.org/10.1002/2015RG000493

Buehler, T., Raible, C. C., \& Stocker, T. F. (2011). The relationship of winter season North Atlantic blocking frequencies to extreme cold or dry spells in the ERA-40. Tellus, 63A, 212-222. https://doi.org/10.1111/j.1600-0870.2010.00492.x

Cai, M., \& Ren, R.-C. (2007). Meridional and downward propagation of atmospheric circulation anomalies. Part I: Northern hemisphere cold season variability. Journal of the Atmospheric Sciences, 64, 1880-1901. https://doi.org/10.1175/JAS3922.1

Cai, M., Yu, Y., Deng, Y., van den Dool, R. R. H. M., Saha, S., Wu, X., \& Huang, J. (2015). Feeling the pulse of the stratosphere: An emerging opportunity for predicting continental-scale cold-air outbreaks 1 month in advance. Bulletin of the American Meteorological Society, 97, 1475-1489. https://doi.org/10.1175/BAMS-D-14-00287.1

Cassou, C. (2008). Intraseasonal interaction between the Madden-Julian Oscillation and the North Atlantic Oscillation. Nature, $455,523-527$. https://doi.org/10.1038/nature07286

Cattiaux, J., Vautard, R., Cassou, C., Yiou, P., Masson-Delmotte, V., \& Codron, F. (2010). Winter 2010 in Europe: A cold extreme in a warming climate. Geophysical Research Letters, 37, L20704. https://doi.org/10.1029/2010GL044613

Cavalieri, D. J., \& Parkinson, C. L. (2012). Arctic sea ice variability and trends, 1979-2010. The Cryosphere, 6, 881-889. https://doi.org/10.5194/tc-6-881-2012

Cellitti, M. P., Walsh, J. E., Rauber, R. M., \& Portis, D. H. (2006). Roll and cell convection in wintertime Arctic cold-air outbreaks. Journal of Geophysical Research, 111, D02114. https://doi.org/10.1029/2005JD006273 
Dacre, H. F., \& Gray, S. L. (2009). The spatial distribution and evolution characteristics of North Atlantic cyclones. Monthly Weather Review, 137, 99-115. https://doi.org/10.1175/2008MWR2491.1

Fauria, M. M., Grinsted, A., Helama, S., Moore, J., Timonen, M., Martma, T., et al. (2010). Unprecedented low twentieth century winter sea ice extent in the Western Nordic Seas since AD 1200. Climate Dynamics, 34, 781-795. https://doi.org/10.1007/s00382-009-0610-z

Ferranti, L., Corti, S., \& Janousek, M. (2015). Flow-dependent verification of the ECMWF ensemble over the Euro-Atlantic sector. Quarterly Journal of the Royal Meteorological Society, 141, 916-924. https://doi.org/10.1002/qj.2411

Fletcher, J., Mason, S., \& Jakob, C. (2016). The climatology, meteorology, and boundary layer structure of marine cold air outbreaks in both hemispheres. Journal of Climate, 29, 1999-2014. https://doi.org/10.1175/JCLI-D-15-0268.1

Grams, C. M., Beerli, R., Pfenninger, S., Staffell, I., \& Wernli, H. (2017). Balancing Europe's wind-power output through spatial deployment informed by weather regimes. Nature Climate Change, 7, 557-562. https://doi.org/10.1038/NCLIMATE3338

Grossman, R. L., \& Betts, A. K. (1990). Air-sea interaction during an extreme cold air outbreak from the eastern coast of the United States. Monthly Weather Review, 118, 324-342. https://doi.org/10.1175/1520-0493(1990)118<0324:AIDAEC >2.0.CO;2

Hanna, E., Cropper, T. E., Jones, P. D., Scaife, A. A., \& Allan, R. (2015). Recent seasonal asymmetric changes in the NAO (a marked summer decline and increased winter variability) and associated changes in the $\mathrm{AO}$ and Greenland Blocking Index. International Journal of Climatology, 35, 2540-2554. https://doi.org/10.1002/joc.4157

Harden, B. E., Renfrew, I. A., \& Petersen, G. N. (2011). A climatology of wintertime barrier winds off southeast Greenland. Journal of Climate, 24, 4701-4717. https://doi.org/10.1175/2011JCLI4113.1

Harden, B. E., Renfrew, I. A., \& Petersen, G. N. (2015). Meteorological buoy observations from the central Iceland Sea. Journal of Geophysical Research: Atmospheres, 120, 3199-3208. https://doi.org/10.1002/2014JD022584

Jahnke-Bornemann, A., \& Brümmer, B. (2009). The Iceland-Lofotes pressure difference: Different states of the North Atlantic low-pressure zone. Tellus $A, 61,466-475$. https://doi.org/10.1111/j.1600-0870.2009.00401.x

Jensen, T. G., Campbell, T. J., Allard, R. A., Small, R. J., \& Smith, T. A. (2011). Turbulent heat fluxes during an intense cold-air outbreak over the Kuroshio Extension Region: Results from a high-resolution coupled atmosphere-ocean model. Ocean Dynamics, 61, 657-674. https://doi.org/10.1007/s10236-011-0380-0

Kidston, J., Scaife, A. A., Hardiman, S. C., Mitchell, D. M., Butchart, N., Baldwin, M. P., \& Gray, L. J. (2015). Stratospheric influence on tropospheric jet streams storm tracks and surface weather. Nature Geoscience, 8, 433-440. https://doi.org/10.1038/ngeo2424

Kim, B. M., Min, S.-K., Jeong, J.-H., Kim, S.-J., Zhang, X., Shim, T., \& Yoon, J.-H. (2014). Weakening of the stratospheric polar vortex by arctic sea-ice loss. International Journal of Climatology, 5, 4646. https://doi.org/10.1038/ncomms5646

Kolstad, E. W. (2017). Higher ocean wind speeds during marine cold air outbreaks. Quarterly Journal of the Royal Meteorological Society, 143, 2084-2092. https://doi.org/10.1002/qj.3068

Kolstad, E. W., \& Bracegirdle, T. J. (2008). Marine cold-air outbreaks in the future: An assessment of IPCC AR4 model results for the Northern Hemisphere. Climate Dynamics, 30, 871-885. https://doi.org/10.1007/s00382-007-0331-0

Kolstad, E. W., Bracegirdle, T. J., \& Seierstad, I. A. (2009). Marine cold-air outbreaks in the North Atlantic: Temporal distribution and associations with large-scale atmospheric circulation. Climate Dynamics, 33, 187-197. https://doi.org/10.1007/s00382-008-0431-5

Kolstad, E. W., Breiteig, T., \& Scaife, A. A. (2010). The association between stratospheric weak polar vortex events and cold air outbreaks in the Northern Hemisphere. Quarterly Journal of the Royal Meteorological Society, 136, 886-893. https://doi.org/10.1002/qj.620

Mallet, P.-E., Claud, C., Cassou, C., Noer, G., \& Kodera, K. (2013). Polar lows over the Nordic and Labrador Seas: Synoptic circulation patterns and associations with North Atlantic-Europe wintertime weather regimes. Journal of Geophysical Research: Atmospheres, 118, 2455-2472. https://doi.org/10.1002/jgrd.50246

Mallet, P.-E., Claud, C., \& Vicomte, M. (2017). North Atlantic polar lows and weather regimes: Do current links persist in a warmer climate? Atmospheric Science Letters, 18, 349-355. https://doi.org/10.1002/asl.763

Michel, C., \& Rivière, G. (2011). The link between Rossby wave breakings and weather regime transitions. Journal of the Atmospheric Sciences, 68, 1730-1748. https://doi.org/10.1175/2011JAS3635.1

Michel, C., Terpstra, A., \& Spengler, T. (2018). Polar mesoscale cyclone climatology for the Nordic Seas based on the ERA-Interim reanalysis. Journal of Climate, 31, 2511-2531. https://doi.org/10.1175/JCLI-D-16-0890.1

Michelangeli, P.-A., Vautard, R., \& Legras, B. (1995). Weather regimes: Recurrence and quasi stationarity. Journal of the Atmospheric Sciences, 52, 1237-1256. https://doi.org/10.1175/1520-0469(1995)052<1237:WRRAQS>2.0.CO;2

Moore, G. W. K., Våge, K., Pickart, R. S., \& Renfrew, I. A. (2015). Decreasing intensity of open-ocean convection in the Greenland and Iceland seas. Nature Climate Change, 5, 877-882. https://doi.org/10.1038/nclimate2688

Papritz, L. (2017). Synoptic environments and characteristics of cold air outbreaks in the Irminger Sea. International Journal of Climatology, 37(Suppl. 1), 193-207. https://doi.org/10.1002/joc.4991

Papritz, L., Pfahl, S., Sodemann, H., \& Wernli, H. (2015). A climatology of cold air outbreaks and their impact on air-sea heat fluxes in the high-latitude South Pacific. Journal of Climate, 28, 342-364. https://doi.org/10.1175/JCLI-D-14-00482.1

Papritz, L., \& Spengler, T. (2017). A Lagrangian climatology of wintertime cold air outbreaks in the Irminger and Nordic seas and their role in shaping air-sea heat fluxes. Journal of Climate, 30, 2717-2737. https://doi.org/10.1175/JCLI-D-16-0605.1

Rasmussen, E., \& Turner, J. (2003). Polar lows: Mesoscale weather systems in the polar regions (p. 612). Cambridge UK: Cambridge University Press.

Renfrew, I. A., \& Moore, G. W. K. (1999). An extreme cold-air outbreak over the Labrador Sea: Roll vortices and air-sea interaction. Monthly Weather Review, 127, 2379-2394. https://doi.org/10.1175/1520-0493(1999)127<2379:AECAOO>2.0.CO;2

Rigor, I. G., Wallace, J. M., \& Colony, R. L. (2002). Response of sea ice to the Arctic Oscillation. Journal of Climate, 15, 2648-2663. https://doi.org/10.1175/1520-0442(2002)015<2648:ROSITT>2.0.CO;2

Shapiro, M. A., Fedor, L. S., \& Hampel, T. (1987). Research aircraft measurements of a polar low over the Norwegian Sea. Tellus, 39A, 272-306. https://doi.org/10.1111/j.1600-0870.1987.tb00309.x

Sprenger, M., \& Wernli, H. (2015). The Lagrangian analysis tool LAGRANTO-version 2.0. Geoscientific Model Development, 8, 1893-1943. https://doi.org/10.5194/gmdd-8-1893-2015

Terpstra, A., Michel, C., \& Spengler, T. (2016). Forward and reverse shear environments during polar low genesis over the North East Atlantic. Monthly Weather Review, 144, 1341-1354. https://doi.org/10.1175/MWR-D-15-0314.1

Thompson, D. W. J., Baldwin, M. P., \& Wallace, J. M. (2002). Stratospheric connection to Northern Hemisphere wintertime weather: Implications for prediction. Journal of Climate, 15, 1421-1428. https://doi.org/10.1175/1520-0442(2002)015<1421:SCTNHW>2.0.CO;2

Thompson, D. W. J., \& Wallace, J. M. (2001). Regional climate impacts of the northern hemisphere annular mode. Science, 293, 85-89. https://doi.org/10.1126/science.1058958

Vannière, B., Czaja, A., Dacre, H., Woollings, T., \& Parfitt, R. (2016). A potential vorticity signature for the cold sector of winter extratropical cyclones. Quarterly Journal of the Royal Meteorological Society, 142, 432-442. https://doi.org/10.1111/j.1600-0870.2010.00492.x 
Vautard, R. (1990). Multiple weather regimes over the North Atlantic: Analysis of precursors and successors. Monthly Weather Review, 118, 2056-2081. https://doi.org/10.1175/1520-0493(1990)118<2056:MWROTN>2.0.CO;2

Wacker, U., Jayaraman Potty, K. V., Lüpkes, C., Hartmann, J., \& Raschendorfer, M. (2005). A case study on a polar cold air outbreak over Fram Strait using a mesoscale weather prediction model. Boundary-Layer Meteorology, 117, $301-336$. https://doi.org/10.1007/s10546-005-2189-1

Wernli, H., \& Schwierz, C. (2006). Surface cyclones in the ERA-40 dataset (1958-2001). Part I: Novel identification method and global climatology. Journal of the Atmospheric Sciences, 63, 2486-2507. https://doi.org/10.1175/JAS3766.1

Zhang, X., Ikeda, M., \& Walsh, J. E. (2003). Arctic sea ice and freshwater changes driven by the atmospheric leading mode in a coupled sea ice-ocean model. Journal of Climate, 16, 2159-2177. https://doi.org/10.1175/2758.1

Zolina, O., \& Gulev, S. K. (2003). Synoptic variability of ocean-atmosphere turbulent fluxes associated with atmospheric cyclones. Journal of Climate, 16, 2717-2734. https://doi.org/10.1175/1520-0442(2003)016<2717:SVOOTF $>2.0 . C O ; 2$ 